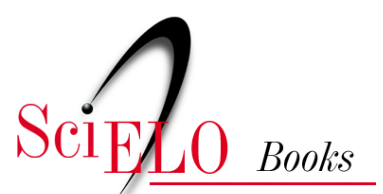

\title{
5. Perfil, histórico e outras informações sobre a revista Ciência \& Saúde coletiva
}

\author{
Maria Cecília de Souza Minayo
}

\section{SciELO Books / SciELO Livros / SciELO Libros}

MINAYO, M. C. S. Perfil, histórico e outras informações sobre a revista Ciência \& Saúde coletiva. In:

LIMA, N. T., and SANTANA, J. P., eds. Saúde coletiva como compromisso: a trajetória da Abrasco [online].

Rio de Janeiro: Editora FIOCRUZ; Abrasco, 2006, pp. 145-161. ISBN: 978-65-5708-156-3.

https://doi.org/10.7476/9786557081563.0006.

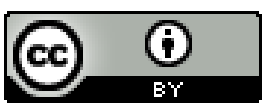

All the contents of this work, except where otherwise noted, is licensed under a Creative Commons Attribution 4.0 International license.

Todo o conteúdo deste trabalho, exceto quando houver ressalva, é publicado sob a licença Creative Commons Atribição 4.0.

Todo el contenido de esta obra, excepto donde se indique lo contrario, está bajo licencia de la licencia $\underline{\text { Creative }}$ Commons Reconocimento 4.0. 


\section{Perfil, Histórico e Outras Informações Sobre a Revista CiÊNCIA \& SAÚDE COLETIVA}

\section{ANTECEDENTES}

A Associação Brasileira de Pós-Graduação em Saúde Coletiva (Abrasco), no decorrer de sua história, sempre teve como uma de suas mais importantes atividades a socialização de conhecimentos e práticas produzidos na área de Saúde Coletiva, de forma muito particular nos congressos (cuja importância é devidamente tratada neste livro), em seminários e outras formas de encontros e reuniões. A divulgação científica, no percurso de sua história, também constituiu uma de suas ações mais importantes, por meio da publicação de documentos resultantes de eventos, parceria com editoras, sobretudo com a Editora Hucitec - que teve um papel muito importante nesse empreendimento desde os anos 80 - e, nos últimos 12 anos, com a Editora Fiocruz. Também fazem parte desse processo coleções publicadas pela própria associação, como a série SaudeMovimento, e publicações avulsas para emitir posicionamentos da associação, por ocasião das Conferências Nacionais de Saúde e de outros eventos importantes em que tem sido necessária sua participação política. Por fim, não menos importantes são os seus boletins (antes apenas em papel e agora

\footnotetext{
${ }^{1}$ Contribuíram para a elaboração deste texto Lilia Maria dos Santos Vicentin (ex-editora executiva da revista Ciência \& Saúde Coletiva), Raimunda M. do Nascimento Mangas (editora executiva da mesma revista) e Thiago de Oliveira Pires, que nos assessorou na parte estatística e de elaboração dos gráficos e tabelas.
} 
em papel e on-line) desde o nascimento da instituição, que acompanham pari passu seu processo de crescimento e, sobretudo, seu envolvimento com as causas da Saúde Coletiva e com a política nacional de saúde.

A discussão sobre a criação de uma revista impressa da própria associação aconteceu no decorrer dos anos 90, condizendo com a etapa do pensamento científico gestado e elaborado sobre Saúde Coletiva. O desejo de promover essa iniciativa tinha respaldo também na experiência da maioria das áreas científicas do país, que, mesmo dispondo de outros periódicos competindo com a divulgação de investigações e debates das disciplinas que representam, criaram seus próprios veículos de comunicação. No entanto, algumas questões contextuais e conjunturais complicavam a colocação em prática do projeto de uma revista específica assinada pela associação. Primeiramente, já havia duas respeitáveis revistas em pleno dinamismo e com reconhecimento nacional e internacional, abrigadas nas mais tradicionais instituições de produção de pesquisa e formação na área: Revista de Saúde Pública, editada pela Faculdade de Saúde Pública da Universidade de São Paulo (USP), que em 2006 completa quarenta anos, e Cadernos de Saúde Pública, com 22 anos em 2006, produzida pela Escola Nacional de Saúde Pública da Fiocruz. Haveria necessidade de uma revista a mais? Haveria espaço para nascimento e crescimento de uma iniciativa tão ousada? Alguns diretores da Abrasco invocavam inclusive a histórica e elevada taxa de 'mortalidade infantil' de periódicos científicos no Brasil e no mundo. Esses eram fortes argumentos que apresentavam, com razão, as sucessivas gestões, quando se encontravam diante das diversas coordenadas para tomada de decisões.

Havia, no entanto, uma questão mais forte que dominava o debate sobre a incerteza quanto à criação da revista. $\mathrm{O}$ mundo todo, desde os anos 80 , vinha passando celeremente pela revolução propiciada pela informática e sobretudo pelo advento da internet. E muitos dos diretores da Abrasco, em suas considerações, partiam do pressuposto - hoje desmentido pela realidade, no mundo inteiro - de que os meios eletrônicos derrubariam a dominância dos escritos em papel. Acrescentavam a tal preocupação outro fator muito importante: a Abrasco sempre foi uma 'pequena empresa social' fazendo grandes negócios, mas permanentemente descapitalizada. A manutenção de uma revista exigiria novos recursos seguros e permanentes.

Os fatos trataram de empurrar a decisão de criar Ciência \& Saúde Coletiva. Logo após o importante Congresso Internacional de Epidemiologia realizado na Bahia em 1995, a Comissão de Epidemiologia da Abrasco colocou em sua pauta a criação imediata de uma revista da subárea. A discussão da diretoria da associação se encaminhou no sentido de, 
obviamente, não cercear o desejo expresso pelos epidemiologistas, mas de, simultaneamente e de uma vez por todas, criar outro periódico que contemplasse todas as subáreas do campo da Saúde Coletiva. Essa decisão levou em conta que, dentro da economia interna da associação, simbolicamente soaria mal a seus membros iniciar a produção de periódicos a partir de apenas uma das disciplinas que compõem o campo da Saúde Coletiva.

Foi assim que, no segundo semestre de 1996, nasceu - numa situação de escassez de recursos e ao mesmo tempo de ousadia - o primeiro número da revista Ciência \& Saúde Coletiva. Ao longo de 1996-1997, considerados como uma espécie de pré-história, foram editados dois números por ano. Nos anos subseqüentes, passaram a ser produzidos quatro números. Em 1998, a Revista Brasileira de Epidemiologia nasceu. Ciência \& Saúde Coletiva já iniciava sua fase de crescimento, de definição de identidade e de consolidação. Ambas contam uma história de sucesso, estão indexadas em bases de dados importantes e vêm servindo à comunidade científica da Saúde Coletiva e à sociedade brasileira, com a divulgação de conhecimentos provenientes de pesquisas, experiências e práticas.

\section{HistóRICO E OBJeTIVOS}

Ciência \& Saúde Coletiva é um espaço científico para discussões, debates, apresentação de pesquisas, exposição de novas idéias e de controvérsias sobre a área. É trimestral e temática - podendo ter suplementos, de acordo com a demanda para isso -, com exceção de um número especial dedicado a temas livres. Nos números temáticos se publicam cerca de 15 artigos, opiniões e resenhas sobre o assunto em foco e mais dez sobre assuntos diversos na seção de temas livres. Cada número contempla aproximadamente 25 textos. Em 2005, por exemplo, 134 artigos foram publicados - porque houve, além dos quatro números habituais, um suplemento - e 334 investigadores e profissionais da área da saúde usufruíram desse meio para divulgação de suas pesquisas e reflexões. Houve um crescimento visível de participação de autores quando se compara, por exemplo, com o ano de 2002, em que a revista passou a ser trimestral: nesse ano foram publicados 67 artigos, totalizando 162 autores. Nos textos há diversas colaborações de autores de países de língua inglesa, francesa e espanhola. Desde sua origem, a revista cumpre fielmente requisitos de periodicidade e de normalização para publicação científica. 
Em 1998 verificaram-se duas decisões editoriais importantes: 1) houve mudança no formato e na padronização da revista. Além de uma nova organização de conteúdo e de espaço que permanecem até hoje, foi criada uma nova capa que lhe deu identidade, desde então, por meio de uma imagem da população brasileira (sintetizando a idéia de 'ciência e Saúde Coletiva') estilizada em meio eletrônico. A cada ano, apenas a cor da capa varia; 2) houve também uma decisão editorial de torná-la uma revista temática. Tal decisão teve por base a proposta da Abrasco de assumir, cientificamente, a discussão do estado do conhecimento sobre assuntos relevantes para o campo da Saúde Pública, investindo na divulgação de pesquisas e debates. Esse nicho específico se coadunava com o papel dessa associação científica e continua a corresponder a ele. Desde então, o formato adotado para dividir o conteúdo da revista evidencia tal propósito. Cada número se inicia com um 'debate' que reúne, em torno de um texto de referência, 'opiniões' de seis a oito especialistas, com os mais diferentes pontos de vista teóricos e práticos. Além dos 'artigos originais' e de 'revisão', o periódico publica uma seção denominada 'Opinião', na qual cabem pontos de vista em forma de pequenos ensaios ou entrevistas com personalidades engajadas no tema do qual trata a revista. A Tabela 1 oferece uma tipologia dos textos publicados desde a origem do periódico.

Até o ano 2001, eram editados dois números por ano de Ciência \& Saúde Coletiva. A partir de 2002 passou-se a publicar quatro números por ano, atendendo a um expressivo crescimento da demanda e respondendo à necessidade de discussão de temas relevantes para o campo da Saúde Coletiva.

A seguir se apresenta um breve resumo, em dados numéricos, do desenvolvimento da revista, permitindo visualizar a sua evolução. 
Tabela 1 - Síntese dos dados

$\begin{array}{llllllllll}1996 & 1997 & 1998 & 1999 & 2000 & 2001 & 2002 & 2003 & 2004 & 2005\end{array}$

Conteúdo da Revista

Artigos originais

Artigos de revisão

\begin{tabular}{llllllllll}
7 & 8 & 18 & 24 & 27 & 24 & 59 & 94 & 98 & 110 \\
\hline
\end{tabular}

Artigos de opinião

Anúncios

Notas técnicas

Resenhas de livros

Notícias gerais

Comunicações

\section{Destino dos Artigos}

Artigos submetidos

Artigos aceitos

Artigos rejeitados

Artigos aguardando publicação

Artigos em processo de avaliação

Tempo entre submissão/ aceitação (meses)

Tempo entre aceitação/ publicação (meses)

Números de pareceristas

\section{Distribuição dos Fascículos}

\begin{tabular}{|c|c|c|c|c|c|c|c|c|c|c|c|}
\hline \multirow{2}{*}{ Doação } & Bibliotecas nacionais & 6 & 6 & 40 & 40 & 60 & 30 & 30 & 60 & 35 & 35 \\
\hline & Bibliotecas estrangeiras & 1 & 1 & 10 & 10 & 12 & 20 & 40 & 40 & 15 & 15 \\
\hline \multirow{4}{*}{ Assinatura } & Bibliotecas nacionais & 6 & 4 & 4 & 10 & 25 & 47 & 48 & 56 & 47 & 64 \\
\hline & Bibliotecas estrangeiras & 1 & 0 & 4 & 3 & 6 & 3 & 3 & 4 & 4 & 8 \\
\hline & Sócios & 1.000 & 800 & 500 & 1.850 & 2.000 & 2.500 & 2.500 & 2.580 & 1.200 & 1.250 \\
\hline & Não-sócios & 20 & 20 & 520 & 20 & 680 & 398 & 398 & 1720 & 2048 & 2058 \\
\hline \multirow{3}{*}{ Permuta } & Revistas nacionais & 20 & 10 & 30 & 30 & 30 & 35 & 30 & 28 & 20 & 28 \\
\hline & Revistas estrangeiras & 10 & 10 & 40 & 40 & 40 & 40 & 40 & 25 & 15 & 12 \\
\hline & Vendas & 40 & 50 & 53 & 100 & 100 & 300 & 280 & 420 & 330 & 380 \\
\hline
\end{tabular}

\begin{tabular}{|c|c|c|c|c|c|c|c|c|c|c|}
\hline \multirow{2}{*}{ Nível / Ano } & \multicolumn{10}{|c|}{ Perfil de Leitores e Assinantes } \\
\hline & 1996 & 1997 & 1998 & 1999 & 2000 & 2001 & 2002 & 2003 & 2004 & 2005 \\
\hline Doutorado & 380 & 420 & 770 & 800 & 935 & 635 & 740 & 1.060 & 1.510 & 2.070 \\
\hline Mestrado & 360 & 380 & 600 & 450 & 580 & 496 & 560 & 910 & 1.364 & 1.320 \\
\hline Especialistas & 180 & 120 & 290 & 195 & 295 & 198 & 198 & 500 & 706 & 618 \\
\hline Graduação & 0 & 0 & 10 & 8 & 10 & 14 & 12 & 8 & 12 & 15 \\
\hline Técnicos & 20 & 22 & 28 & 52 & 108 & 58 & 58 & 120 & 120 & 75 \\
\hline Lato sensu & 100 & 168 & 188 & 215 & 270 & 220 & 220 & 590 & 850 & 700 \\
\hline Profissões & 1996 & 1997 & 1998 & 1999 & 2000 & 2001 & 2002 & 2003 & 2004 & 2005 \\
\hline Médicos & 150 & 160 & 160 & 168 & 178 & 178 & 203 & 247 & 273 & 269 \\
\hline Sanitaristas & 210 & 210 & 267 & 287 & 312 & 333 & 381 & 400 & 465 & 525 \\
\hline Biólogos & 30 & 30 & 30 & 18 & 18 & 21 & 25 & 25 & 29 & 29 \\
\hline Enfermeiros & 60 & 60 & 60 & 60 & 60 & 64 & 94 & 94 & 104 & 116 \\
\hline Pediatras & 30 & 30 & 30 & 30 & 30 & 30 & 60 & 60 & 65 & 68 \\
\hline Professores de Pós-Graduação & 100 & 100 & 155 & 168 & 188 & 188 & 188 & 257 & 307 & 312 \\
\hline Coordenadores de Pós-Graduação & 20 & 20 & 20 & 20 & 25 & 25 & 30 & 35 & 50 & 80 \\
\hline Profissionais de Saúde Pública geral & 75 & 75 & 110 & 153 & 159 & 160 & 165 & 209 & 229 & 295 \\
\hline Bioestatísticos & 40 & 50 & 80 & 108 & 108 & 138 & 148 & 156 & 180 & 180 \\
\hline Epidemiologistas & 90 & 110 & 110 & 125 & 135 & 145 & 145 & 173 & 173 & 183 \\
\hline Odontólogos & 10 & 10 & 12 & 10 & 10 & 0 & 0 & 26 & 36 & 66 \\
\hline Profissionais de gestão em Saúde Pública & 55 & 75 & 120 & 172 & 174 & 178 & 186 & 255 & 264 & 350 \\
\hline Profissionais de medicina preventiva & 50 & 60 & 76 & 94 & 94 & 102 & 140 & 190 & 205 & 205 \\
\hline Cientistas sociais & 120 & 120 & 86 & 107 & 127 & 127 & 151 & 180 & 220 & 248 \\
\hline
\end{tabular}


O Gráfico 1 mostra uma tipologia dos textos publicados pela revista:

Gráfico 1 - Tipologia do conteúdo da revista - 1996-2005

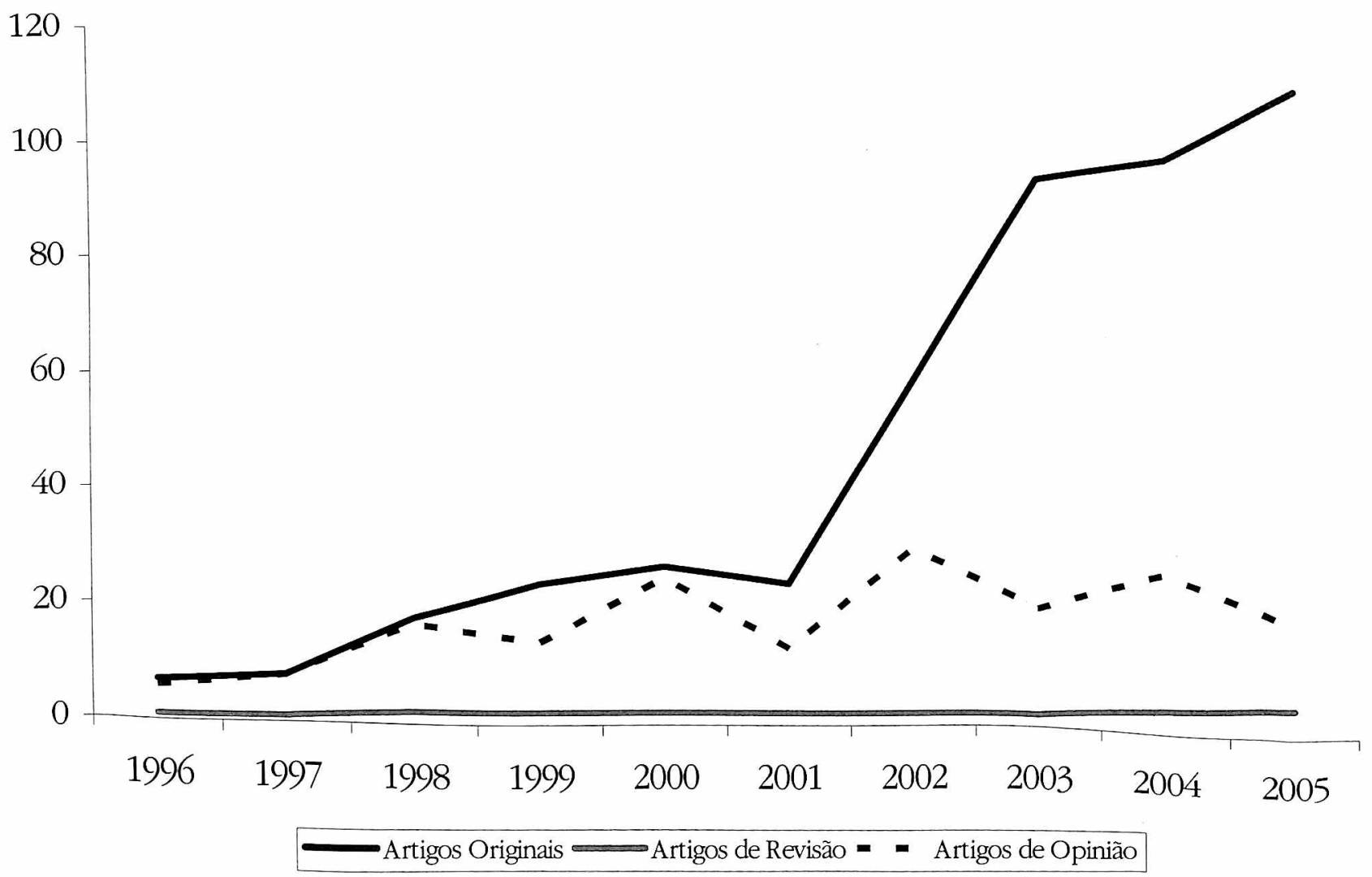

Perfil de Formação e Profissional dos Leitores

Como se pode observar, ao longo dos anos a revista foi 'elitizando' o perfil de seus leitores, o que é bastante compreensível por se tratar de um periódico da Abrasco que reúne todos os programas de mestrado e doutorado da área e pelo fato de serem doutores os que em maioria nela publicam, pelo menos como primeiro autor. Causou preocupação nesse estudo a pouca presença dos leitores dos cursos de graduação, exigindo, com base nessa avaliação, investimento específico nesse público potencial. 
Gráfico 2 - Formação dos leitores da revista - 1996-2005

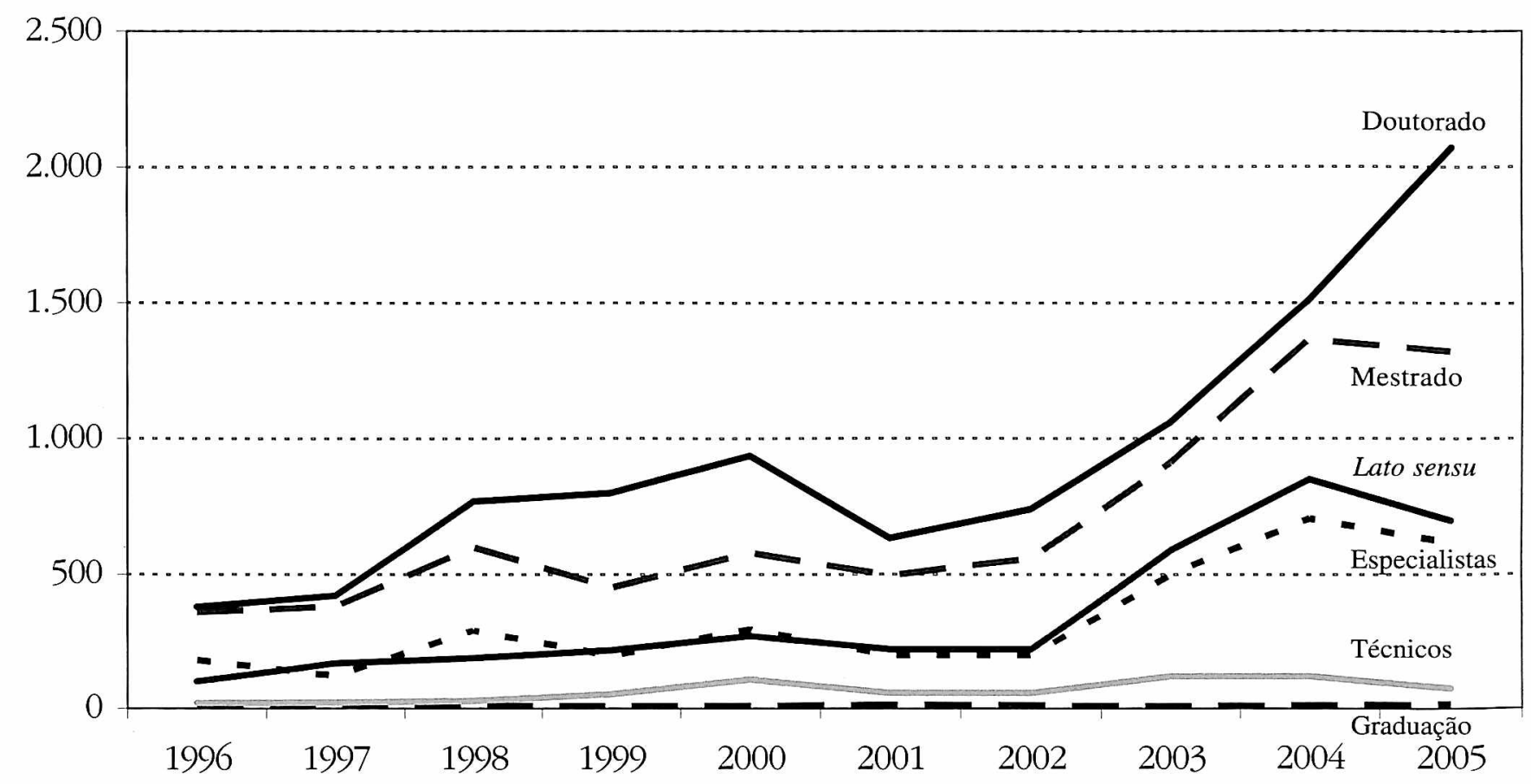

Nos gráficos 2 e 3, apresentam-se os perfís acadêmico e profissional dos leitores, evidenciando que, embora a revista atinja pouco os alunos de graduação, ela é lida por seus mestres e, possivelmente, utilizada por eles em suas aulas. Essa observação não redime a equipe executiva de Ciência \& Saúde Coletiva de criar estratégias para se aproximar mais dos estudantes universitários. 
Gráfico 3 - Inserção profissional dos leitores e assinantes - 1996-2005

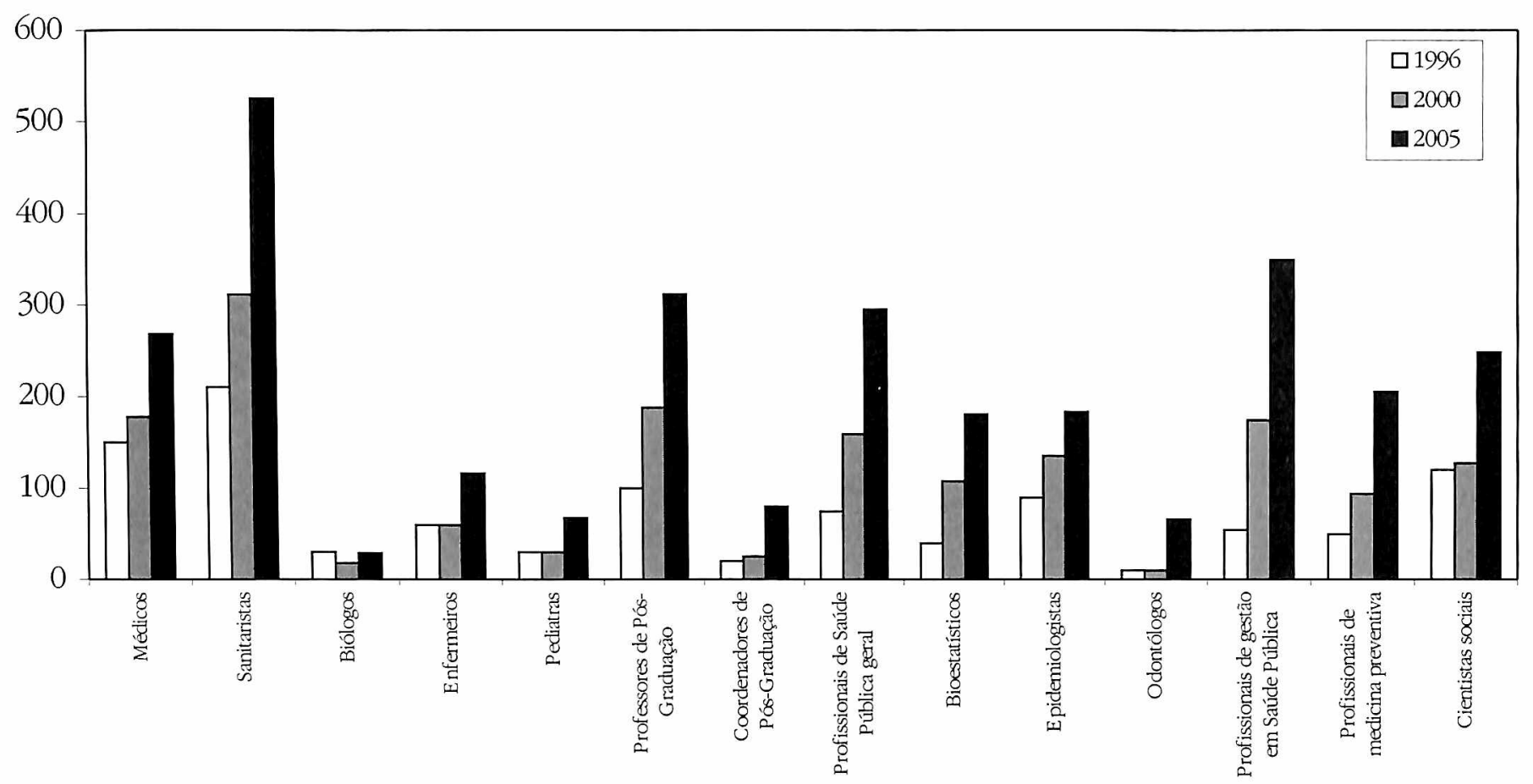

A avaliação mostra a queda no número de assinantes sócios da Abrasco. Isso se deve ao fato de que a instituição só distribui a revista para sócios adimplentes. Os picos correspondem à época dos diversos congressos institucionais em que a associação realiza uma política focalizada de filiação. Em contrapartida, cresceu enormemente o número de assinantes não-sócios e de vendas de números específicos, como pode ser observado no Gráfico 4:

Gráfico 4 - Assinantes sócios da Abrasco e não-sócios - 1996-2005

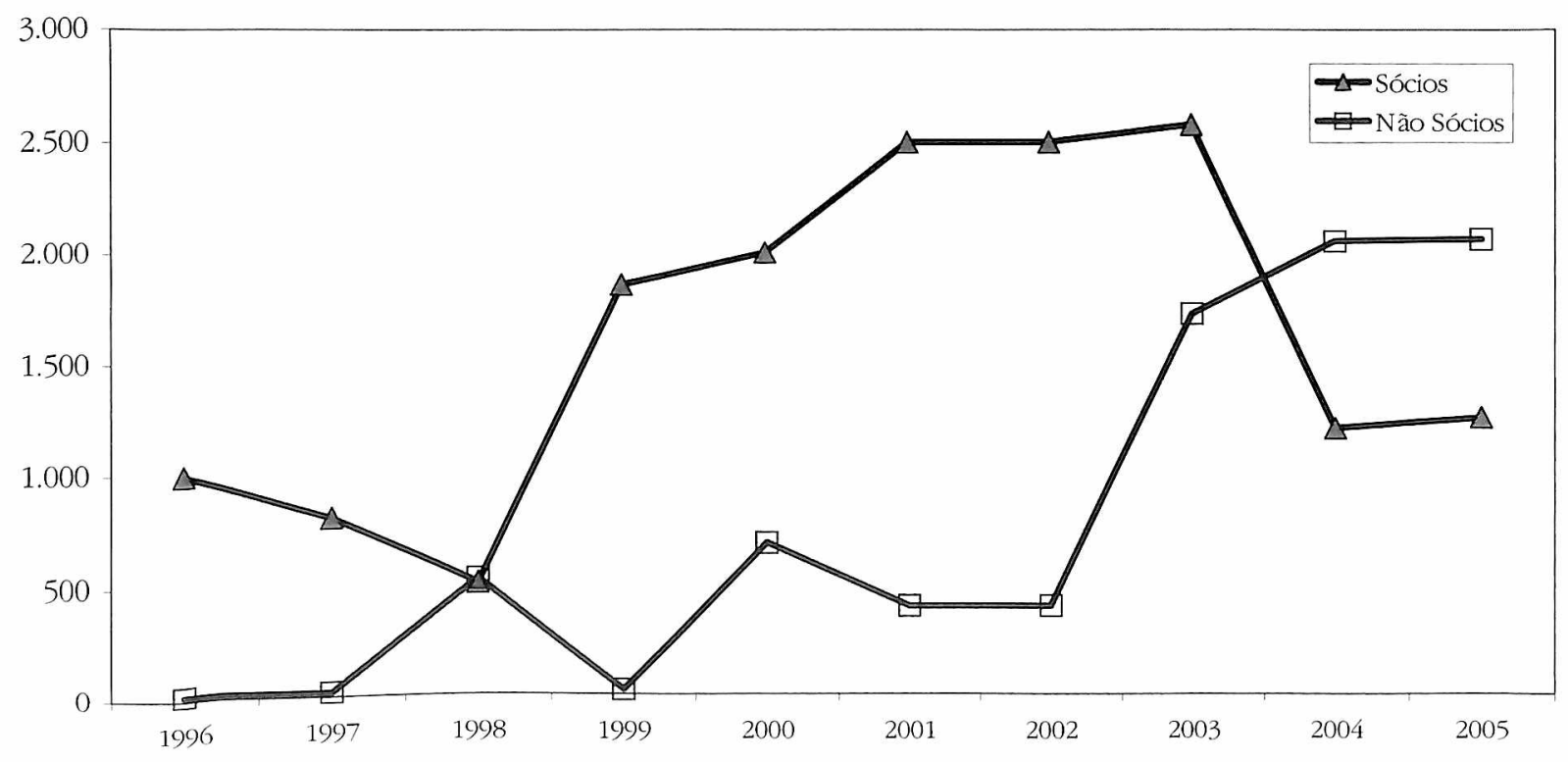




\section{Requisitos de Confiabilidade Científica}

Do ponto de vista científico, a revista segue todos os trâmites reconhecidos internacionalmente. Possui: a) uma editoria científica e uma equipe de editoria executiva. Os procedimentos de revisão técnica, de diagramação e de impressão são terceirizados; b) um corpo de editores associados que respondem pelas áreas principais de desenvolvimento da 'Saúde Coletiva/Pública' no Brasil - epidemiologia, planejamento e gestão de saúde, ciências sociais e saúde, ciência e tecnologia em saúde e ambiente; c) um Conselho Editorial composto por 68 pesquisadores doutores das instituições nacionais de saúde de todo o país e alguns representantes internacionais (Argentina, Peru, Venezuela, Colômbia, México, Chile, Canadá, Estados Unidos, Inglaterra); d) consultores ad hoc. Promove a avaliação por pares de todos os textos recebidos e publicados. O Gráfico 5 mostra a evolução do número de pareceristas que compõem o Conselho Editorial ou são ad hoc.

Gráfico 5 - Evolução do número de pareceristas do Conselho Editorial e ad hoc - 1996-2005

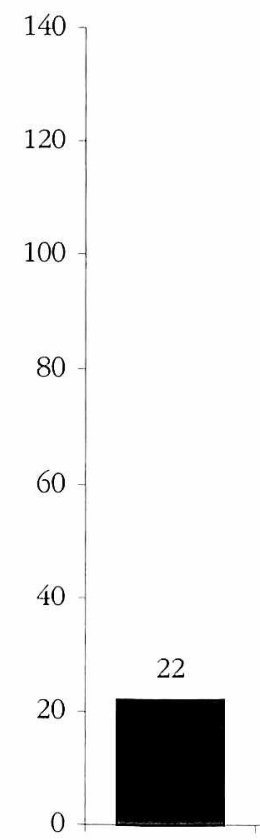

1996

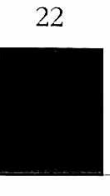

1997
22

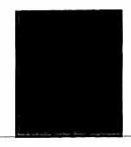

1998

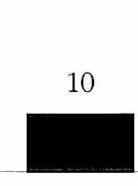

1999

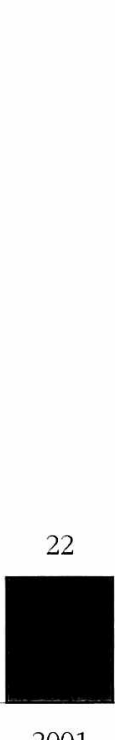

2001

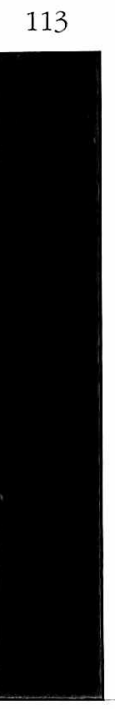

2004
118

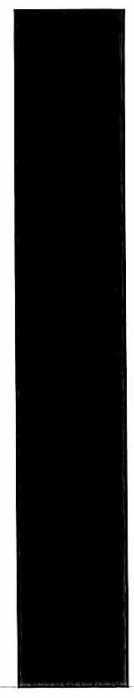

2005 
Cada artigo, logo que recebido pela secretaria executiva: a) é passado por um crivo editorial relativo a sua pertinência ao escopo da revista; b) se pertinente, é protocolado, processado e enviado, sem nome e sem vinculação dos autores, a dois pareceristas que têm vinte dias para se pronunciarem; c) esse artigo ou é devolvido com os devidos pareceres ou a editoria providencia novos consultores, no caso de não adesão dos primeiros; d) em situações de pareceres contraditórios, o artigo segue para um terceiro; e) quando o texto recebe opiniões de não-publicação ou demanda mudanças muito substanciais, ele é recusado pelo editor científico; f) quando as modificações solicitadas são pequenas e contribuem para o aperfeiçoamento do artigo, este é devolvido aos autores para as providenciarem; g) no caso de aceite do texto sem correções, ele entra, logo a seguir, numa lista dos que irão ser publicados.

No Gráfico 6, de forma evolutiva, pode-se visualizar o balanço entre o número de artigos recebidos, aceitos, rejeitados e publicados.

Gráfico 6 - Dinâmica de tratamento dos artigos - 1996-2005

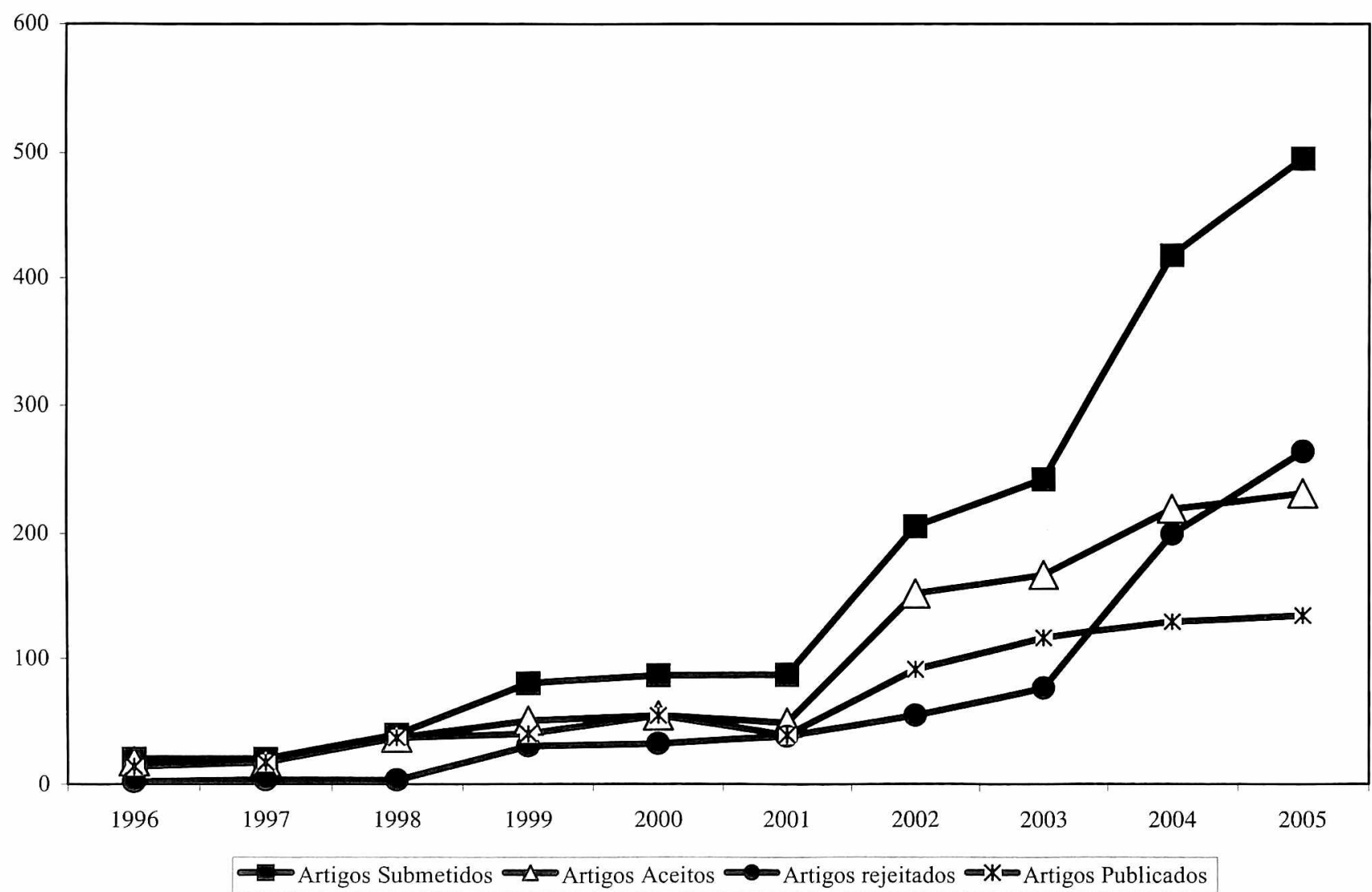


No Gráfico 7, pode-se acompanhar também no tempo o fluxo entre a submissão de um artigo e sua publicação, no caso dos aprovados.

Gráfico 7 - Fluxo médio de tempo entre submissão e publicação de um artigo - 1996-2005

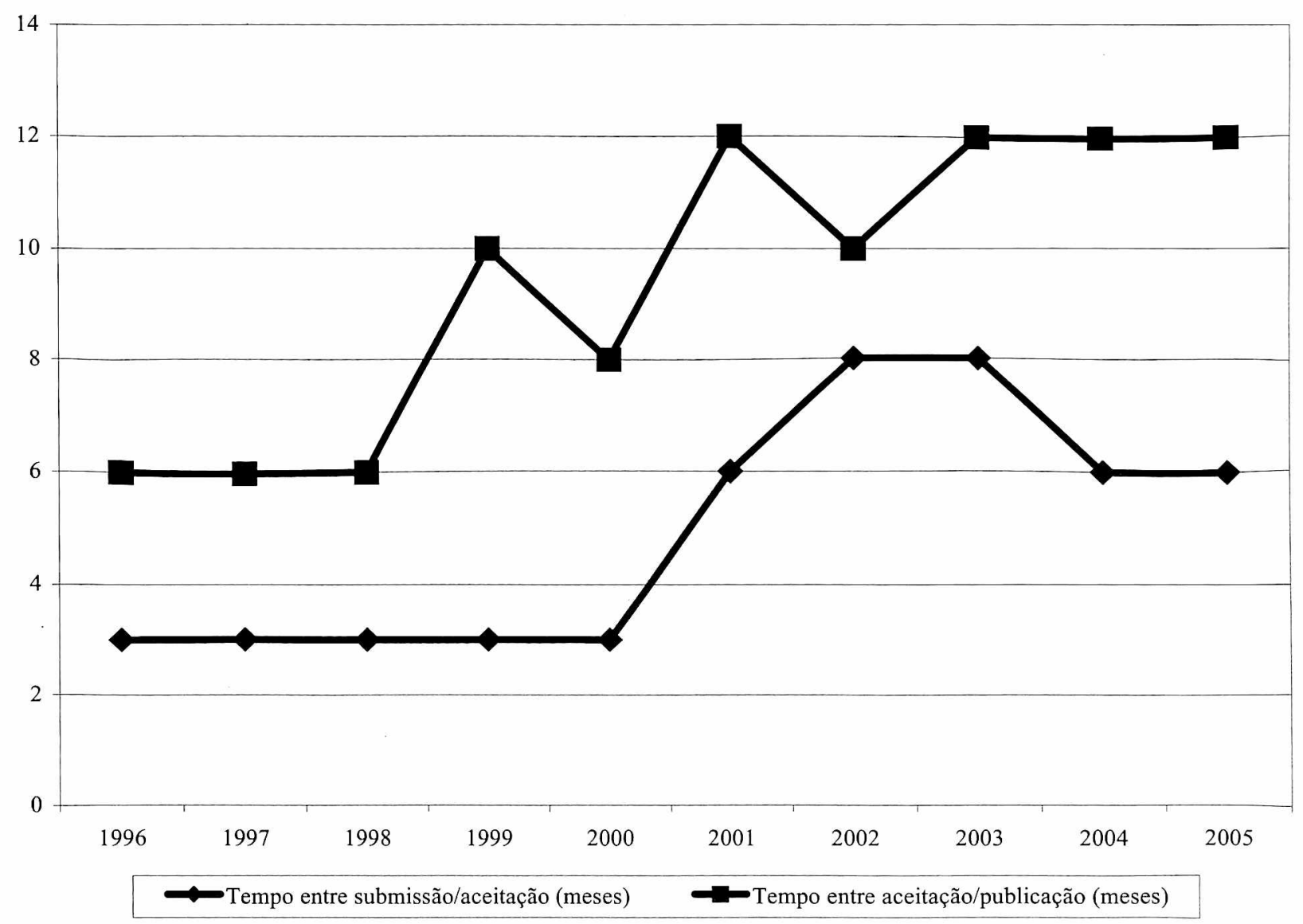

\section{Procedimentos para Publicação dos Números Temáticos}

Para cada número temático são convidados um ou mais editores, importantes especialistas no tema em questão. Esses editores inicialmente produzem um 'termo de referência', estabelecendo o objetivo, o sentido e a importância do assunto em pauta, escolhendo os articulistas e debatedores. Esse termo de referência é preparado em comum acordo com a editoria científica e enviado para os editores associados, que o lêem, criticam, opinam e, se for o caso, sugerem modificações. Uma vez aprovado o termo de referência, é estabelecida a data para sua divulgação dentro do 
cronograma anual da revista, e os editores convidados passam a ser coresponsáveis, com a editoria científica, pela produção do número em questão. É importante esclarecer que, nos números temáticos, todos os artigos 'também passam por pareceristas', e os autores que são solicitados a apresentar artigos já sabem dessa condição para participar da iniciativa.

Em seu nascimento, a revista divulgava debates e temas livres. A partir de 1998 a ênfase vem recaindo em abordagens temáticas, e hoje são 27 os números que constituem o acervo de publicações de Ciência \& Saúde Coletiva.

1996 (1): Temas livres e debate sobre o SUS.

1997 (1/2): Avaliação da pós-graduação em Saúde Coletiva.

1998 (1): Temas livres e debate sobre transdisciplinaridade.

1998 (2): Saúde e ambiente no processo de desenvolvimento.

1999 (1): 'É possível prevenir a violência?'

1999 (2): Gestão do SUS: problemas, desafios e avanços.

2000 (1): Qualidade de vida e saúde.

2000 (2): 100 anos de Saúde Pública no Brasil.

2001 (1): O sujeito e a subjetividade na práxis da saúde.

2001 (2): A política de saúde no Brasil na década de 90.

2002 (1): Genética e Saúde Pública: desafios e perspectivas.

2002 (2): Temas atuais em Saúde Pública (temas livres).

2002 (3): Desafios da gestão local do sistema de saúde.

2002 (4): Acesso e uso de serviços de saúde no Brasil: análise da PNAD/98.2

2003 (1): Ciências sociais e saúde na América Latina na contemporaneidade.

2003 (2): Economia e gestão da política de saúde no Brasil.

2003 (3): Múltiplas abordagens em Saúde Coletiva (temas livres).

2003 (4): Integrando saúde do trabalhador e saúde ambiental:

Observatório das Américas.

2004 (1): Ética e humanização em saúde (temas livres).

2004 (2): Pesquisa em saúde no Brasil: problematizando ciência \& tecnologia do setor.

2004 (3): Perspectivas da avaliação em promoção da saúde.

2004 (4): Doenças crônicas não-transmissíveis.

2005 (1): Saúde do homem: alerta e relevâncias.

2005 (2): Análise de serviços, políticas e problemas (temas livres).

2005 (3): Humanização e produção de cuidados em saúde.

2005 (4): Saúde do trabalhador brasileiro: velhos e novos problemas.

2005 (supl.): Saúde, trabalho e ambiente.

2 Pesquisa Nacional de Amostra por Domicílios do Instituto Brasileiro de Geografia e Estatística (IBGE). No caso do objeto de estudo dessa revista, a pesquisa foi sobre saúde e serviços de saúde. 
O Gráfico 8 apresenta o perfil do conteúdo editado por Ciência \& Saúde Coletiva. É claro que a classificação e o agrupamento dos temas realizados pela editoria podem ter privilegiado algumas tendências. Apesar dessa contingência, ficam patentes que os textos divulgados correspondem ao campo da Saúde Coletiva, no qual, persistentemente, se encontram problemas de delimitação de fronteiras. No período em questão, esse problema ocorre e é permanente.

Gráfico 8 - Temas tratados na revista - 1996-2005

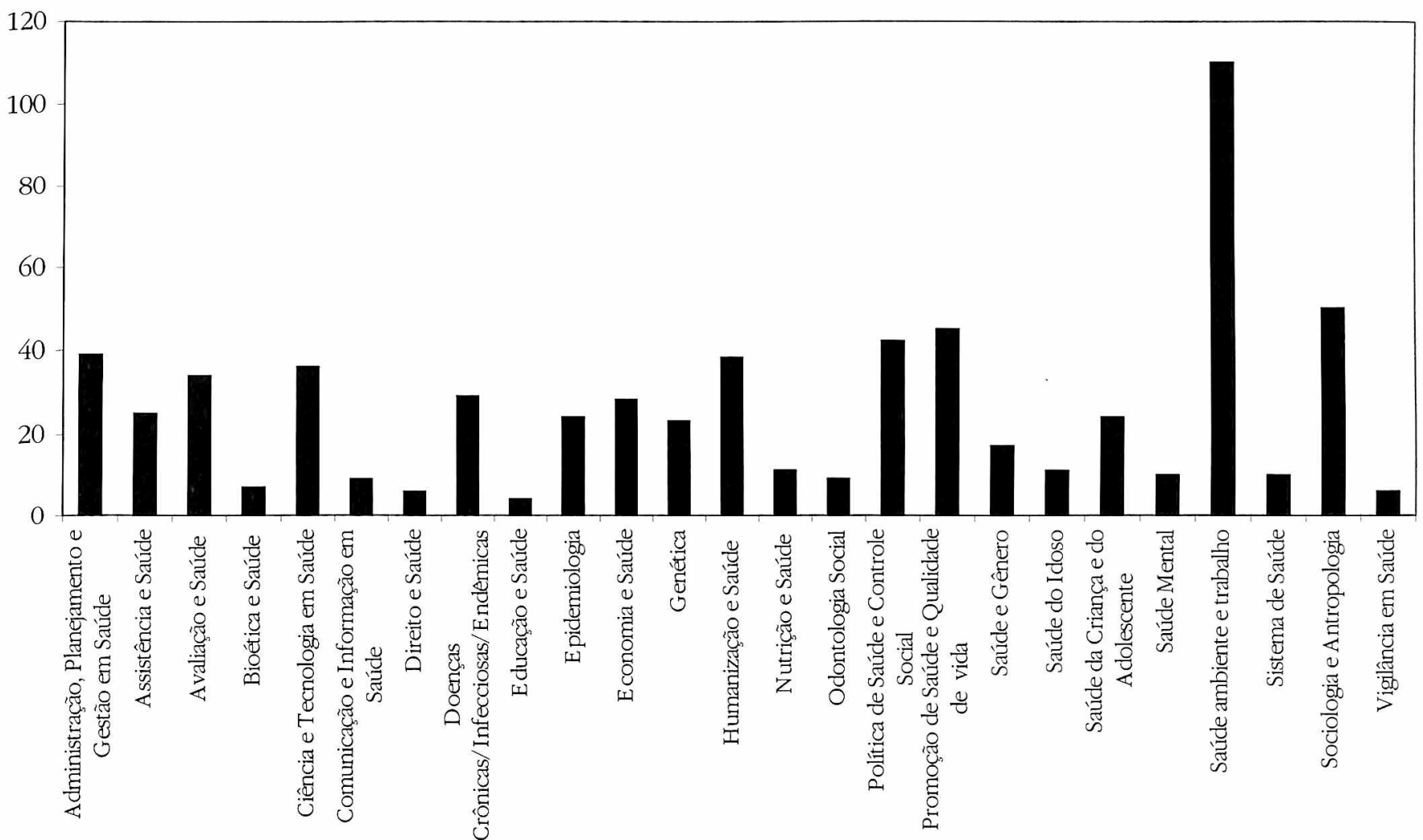

Nas páginas finais de cada exemplar são divulgados, durante todo o ano, pequenos resumos sobre os números temáticos em processo de produção. Essa iniciativa possibilita que pesquisadores do Brasil e de outros países enviem sua contribuição, ainda que não tenham sido convidados pelos editores, induzindo-se, assim, uma oferta espontânea de textos que são incorporados à edição temática. 


\section{FinANCIAMENTO}

Ciência \& Saúde Coletiva é financiada, em parte, pela Abrasco, que a mantém por meio de assinaturas nacionais e internacionais, institucionais e individuais. Mais duas instituições, em toda a história do periódico, têm sido fundamentais para garantir seu sucesso, pontualidade na entrega e qualidade editorial: a Fundação Oswaldo Cruz, que sedia sua secretaria executiva e a apóia institucionalmente, e o Conselho Nacional de Desenvolvimento Científico e Tecnológico (CNPq), que desde o seu início vem colaborando com sua avaliação, o que constitui um selo de qualidade e assegura parte de seu financiamento. Além dessas duas entidades, o Ministério da Saúde freqüentemente colabora com o financiamento de números que lhe atendem a interesses específicos.

\section{TIRAGEM}

A tiragem do periódico é hoje de três mil exemplares, o que se pode considerar um sucesso, pelo menos na América Latina. Além dos sócios da Abrasco, há cerca de quatrocentas assinaturas institucionais e individuais e um elevado número de assinaturas ou compras por parte de não-sócios, além de um pequeno montante de permuta e distribuição para bibliotecas nacionais e estrangeiras, como indicado anteriormente. Quando existe interesse de alguma instituição por números específicos, há um aumento ocasional da tiragem. É o caso, por exemplo, da última de 2005 (10.4/2005), que trata de "Saúde do Trabalhador: velhos e novos problemas". O Ministério da Saúde demandou dois mil exemplares extras, para serem distribuídos aos delegados da III Conferência Nacional de Saúde dos Trabalhadores.

\section{INDEXAÇÃo}

Atualmente, Ciência \& Saúde Coletiva está indexada na base Scielo (desde 2002) e em várias outras bases, como Lilacs (Biblioteca LatinoAmericana de Ciências da Saúde), Latindex (Sistema Regional de Información em Línea para Revistas Científicas de América Latina y el Caribe, Portugal e España), Red ALCyC (Rede de Periódicos Científicos América Latina y el Caribe, Portugal y España) e CSA (Sociological Abstract), CAB International/Global Health Abstracts (Commonwealth Agricultural and Apllied Sciences Database \& Global Health International 
Public Health Database), Repdisca (Sanitary Engineering and Environmental Sciences Documentation Collection) e Doarj (Diretory of Open Access Journals). Aguarda-se resposta ao pedido de indexação da revista no Medline (U.S. National Library of Medicine).

\section{Visão de Futuro E Parcerias}

Desde 2005 vem-se trabalhando para que a revista atinja um patamar a mais em seu aprimoramento e qualidade. Trabalhou-se para que Ciência \& Saúde Coletiva pudesse entrar no ano 2006 com um plano de modernização em vários sentidos: a) informatização de todos os procedimentos editoriais, o que já está ocorrendo; b) plena vigência (o que já está acontecendo desde janeiro de 2006) do endereço eletrônico <http:// www.cienciaesaudecoletiva.com.br $>$, no qual artigos estão sendo aceitos on-line, há divulgação permanente de notícias que interessam ao público da revista, informações sobre todas as publicações anteriores, links para parceiros e todas as bases de indexação. Sobretudo, é o local onde estão sendo divulgados todos os textos aprovados por pareceristas e em compasso de espera para publicação em papel. O importante desta última iniciativa é que os autores podem citar esses artigos que forem colocados na revista on-line, valendo-lhes para compor seu currículo; c) um grau mais elevado de internacionalização no que se refere a autores, colaborações e composição do Conselho Editorial; d) parceria com várias outras revistas científicas, dentre elas Environmental Health Perspective, Revista de Salud Pública (México), Ciencia y Trabajo (Chile), Salud Colectiva (Argentina), Revista Brasileira de Epidemiologia (da Abrasco), Cadernos de Saúde Pública e Revista de Saúde Pública do Brasil. Com a primeira, a parceria implica a publicação, em ambas, de artigos de revisão do estado de conhecimento de determinados temas sobre saúde e ambiente. Em relação às outras, a parceria consiste, nesse primeiro momento, na divulgação mútua de produtos, artigos e eventos que cada uma apóia. Constitui ainda um projeto de elevado interesse e investimento imediato a divulgação, para a mídia, dos achados publicados em artigos de pesquisa, dentro do espírito público que consagrou a Abrasco no Brasil, produzindo Ciência \& Saúde Coletiva para a Sociedade. Este é o slogan que abre a página da revista on-line. 


\section{CONCLUSÕES}

É difícil falar de uma obra quando se está inteiramente imerso nela. Mas, para atenuar o viés emocional de quem cuida da revista como quem cuida de uma filha, este texto foi lido, apreciado e corrigido pelos editores associados da publicação. Muito foi feito e há muito por fazer no crescimento e aprimoramento de Ciência \& Saúde Coletiva. Um ponto fraco que foi detectado pela pesquisa que deu origem a este texto é o processo de divulgação dos importantes artigos e outros tipos de material produzido. Ele é ainda muito endógeno, atinge os iniciados da área, mas não a população em geral, e muito pouco os estudantes de graduação.

Também muitas lições foram aprendidas. A primeira delas apaga o medo que, em algum momento, a diretoria tinha ao investir nessa façanha. O tempo mostrou que, em todas as áreas editoriais, a internet não acabou com a comunicação escrita. Pelo contrário, em todo o mundo, inclusive no Brasil, cresceu e está crescendo a indústria editorial impressa (também a científica), que potencializa as publicações virtuais e é potencializada por elas. A revista Ciência \& Saúde Coletiva, da Abrasco, no pouco tempo de divulgação on-line, é prova dessa sintonia e dessa convergência de mídias.

Outra lição veio do reconhecimento da importância das parcerias. Hoje, Ciência \& Saúde Coletiva tem link no site para todas as instituições parceiras e bases de indexação, permitindo-lhe um crescimento no processo de divulgação e internacionalização.

O respeito e o carinho dos autores e leitores, as sábias orientações do seu corpo de editores e conselheiros, a dedicação incomensurável de seu grupo executivo, o apoio das sucessivas diretorias da Abrasco tornaramna imprescindível no mercado das idéias em Saúde Coletiva no Brasil. Seu formato temático, captando os assuntos de profundo e indiscutível interesse para o debate e para o conhecimento em Saúde Coletiva, faz a diferença e lhe reserva um nicho privilegiado no fervilhar das idéias e das pesquisas em saúde.

Dessa forma, comemorando dez anos e rememorando seu início pequeno e tímido - sem esquecer que, até hoje, o financiamento de cada número é também uma façanha -, pode-se dizer que valeu a pena a Abrasco acreditar nesse projeto. O futuro, cujas coordenadas não dependem apenas da associação, mas do próprio mover do campo da ciência e tecnologia e, sobretudo, do mercado de divulgação científica, está aberto. No entanto, as bases da construção são sólidas e inquebrantáveis. 


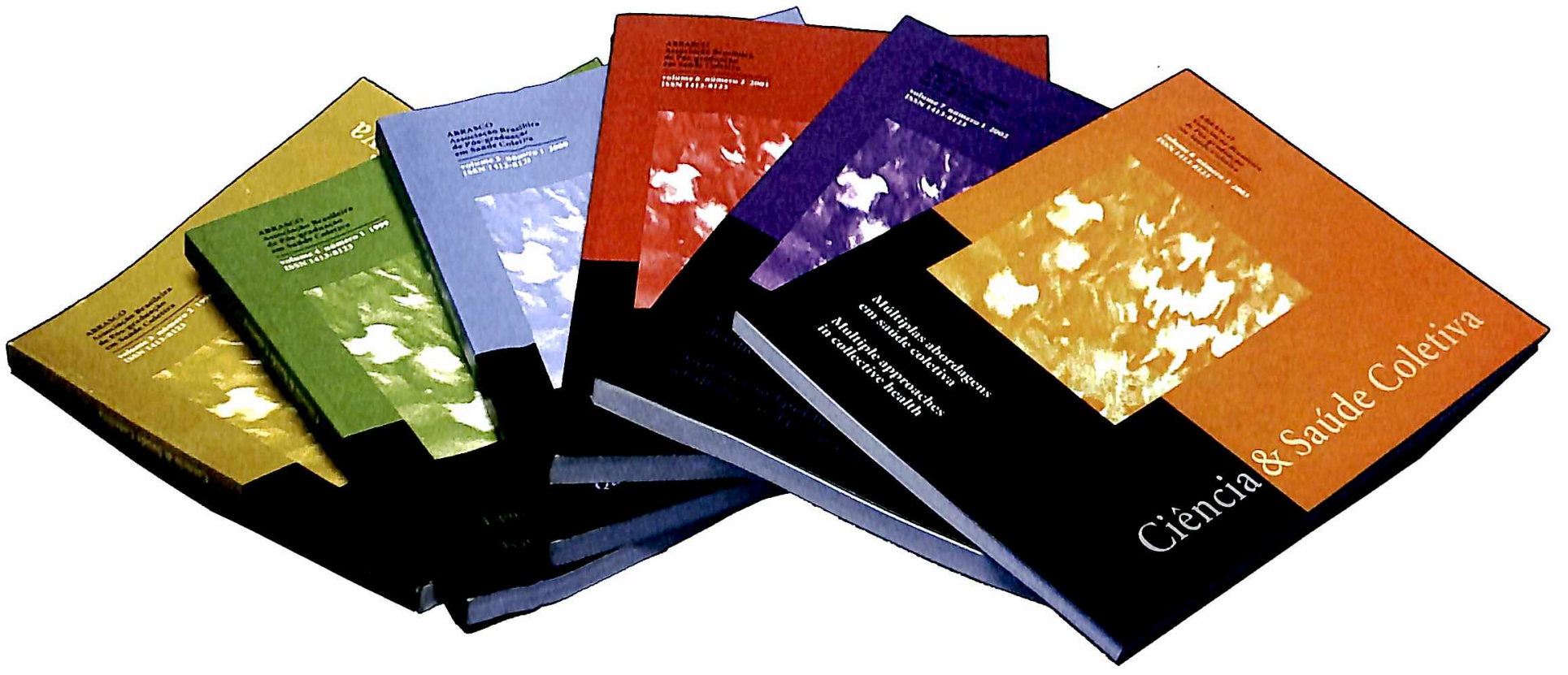

Imagem 15 